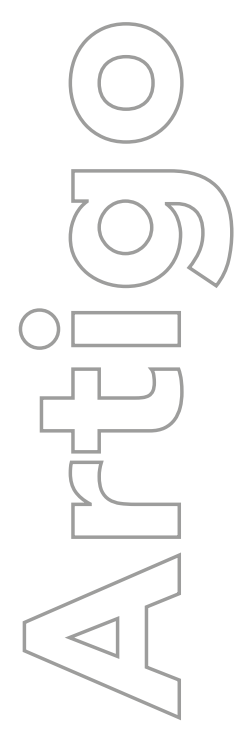

revista

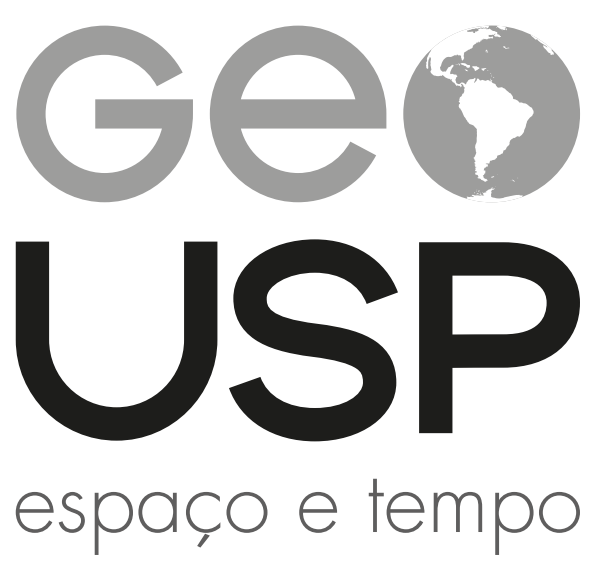

Volume $23 \cdot n^{\circ} 3$ (2019)

ISSN 2179-0892

\section{Autocorrelação espacial entre indicadores socioeconômicos nos vales do Jequitinhonha e Mucuri}

\author{
Samuel Ferreira da Fonseca \\ Universidade Federal do Tocantins \\ Heloisa Helena de Aguiar \\ Universidade Federal dos \\ Vales do Jequitinhonha e Mucuri
}

p. 619-639

Como citar este artigo:

FONSECA, S. F; AGUIAR, H. H. Autocorrelação espacial entre indicadores socioeconômicos nos vales do Jequitinhonha e Mucuri. Geousp - Espaço e Tempo (Online), v. 23, n. 3, p. 619-639, dez. 2019, ISSN 2179-0892.

Disponível em: https://www.revistas.usp.br/geousp/article/view/137849. doi: https://doi.org/10.11606/issn.2179-0892.geousp.2019.137849.

\section{(c) $($ i) $(9)$}

Este artigo está licenciado sob a Creative Commons Attribution 4.0 Licence 


\title{
Autocorrelação espacial entre indicadores socioeconômicos nos vales do Jequitinhonha e Mucuri
}

\section{Resumo}

Este trabalho apresenta a análise exploratória espacial de dados socioeconômicos das mesorregiões vales do Jequitinhonha e Mucuri. O procedimento metodológico consistiu em revisão bibliográfica e tratamento estatístico de dados secundários (renda per capita média; razão de dependência demográfica; proporção de extremamente pobres e taxa de envelhecimento populacional). Aplicaram-se o índice de Moran global e o indicador de associação espacial local, e se usaram os aplicativos: GeoDa 1.8.10 ${ }^{\mathrm{TM}}$, TerraView 4.2.2 $2^{\mathrm{TM}}$ e ArcGIS 9.3 ${ }^{\mathrm{TM}}$. Verificou-se autocorrelação espacial de renda per capita média nas municipalidades de Carlos Chagas e Nanuque com grau de confiança entre 95 e 99,9\% em 1991 e 2010. Novo Cruzeiro, Caraí, Itaipé, Joaíma e Ponto dos Volantes foram identificados como áreas de dependência espacial segundo a proporção de extremamente pobres. Sugere-se que se façam amostragens nos municípios em situação crítica para confirmar ou refutar estas conclusões.

Palavras-chave: Índice de Moran. Associação espacial local. Vale do Jequitinhonha.

\section{Spatial autocorrelation between socioeconomic indicators in the Jequitinhonha and Mucuri valleys}

\begin{abstract}
The aim of this paper is the exploratory spatial analysis of socioeconomic data from the Jequitinhonha and Mucuri valleys mesoregions. As a methodological procedure, a bibliographic review and statistical treatment of secondary data were used (average per capita income, demographic dependence ratio, extremely poor proportion and population aging rate). The global Moran index and the local spatial association indicator were applied. Applications were used: GeoDa 1.8.10 ${ }^{\mathrm{TM}}$, TerraView 4.2.2 $2^{\mathrm{TM}}$ and ArcGIS 9.3 ${ }^{\mathrm{TM}}$. In the municipalities of Carlos
\end{abstract}


Chagas and Nanuque, with a confidence level between 95 and 99.9\%, for 1991 and 2010, the autocorrelation of the per capita average income was verified. Novo Cruzeiro, Caraí, Itaipé, Joaíma and Ponto dos Volantes were identified as areas of spatial dependence for the extremely poor proportion. It is suggested that sampling should be carried out in municipalities in critical situations in order to reinforce or refute the conclusions drawn from this paper.

Keywords: Moran index. Local space association. Jequitinhonha Valley.

\section{Autocorrelación espacial entre indicadores socioeconómicos en los valles del Jequitinhonha y Mucuri}

\section{Resumen}

El objetivo de este trabajo comprende el análisis exploratorio espacial de datos socioeconómicos de las mesorregiones Valles del Jequitinhonha y Mucuri. Como procedimiento metodológico se utilizó revisión bibliográfica y tratamiento estadístico de datos secundarios (rendimiento per capita media, razón de dependencia demográfica, proporción de extremadamente pobres y tasa de envejecimiento poblacional). Se aplicó el índice de Moran global y el indicador de asociación espacial local. Se utilizaron las aplicaciones: GeoDa 1.8.10 ${ }^{\mathrm{TM}}$, TerraView 4.2.2 ${ }^{\mathrm{TM}}$ y ArcGIS 9.3 ${ }^{\mathrm{TM}}$. Se verificó autocorrelación espacial de Renta Per Capita Media en las municipalidades de Carlos Chagas y Nanuque con grado de confianza entre 95 a 99,9\%, para 1991 y 2010. Novo Cruzeiro, Caraí, Itaipé, Joaíma y Ponto dos Volantes fueron identificados como áreas de dependencia espacial para la proporción de extremadamente pobres. Se sugiere que los muestreos se realicen en los municipios en situaciones críticas con el fin de reforzar o refutar las conclusiones oriundas de este trabajo.

Palabras clave: Índice de Moran. Asociación espacial local. Vale de Jequitinhonha. 


\section{Introdução}

Os sistemas de informações geográficas (SIG) ganharam espaço significativo na análise espacial. Uma de suas características é permitir a atualização dos produtos cartográficos de modo rápido e prático e, portanto, a melhor compreensão dos fenômenos espaciais (Rosa, 2005; Fonseca; Santos, D.; Hermano, 2013; Fonseca; Santos, D.; Trindade, 2014; Fonseca; Hermano; Silva, A. C., 2016; Fonseca et al., 2016; Fonseca; Silva, A. C.; Senna, 2018). Após o advento do SIG, observar mudanças espaciais ao longo de certo período de tempo tornou-se elementar.

A identificação dos padrões de dependência espacial para variáveis socioeconômicas merece atenção, pois permite apontar novas ações de planejamento e desenvolvimento regional. Para identificar autocorrelação espacial entre municípios é utilizada a abordagem do Índice de Moran (Anselin, 1995; Silva, A. B., 2003; Chen, Y., 2013; Chen, X. et al., 2015). O referido índice aponta dependência espacial entre as áreas analisadas (Anselin, 1995; Chen, Y., 2013). Assim, seu uso é fundamental para detectar clusters (agrupamentos) para indicadores socioeconômicos entre entidades espaciais.

Neste trabalho, usaram-se SIG e análise da associação espacial para identificar autocorrelação espacial entre indicadores socioeconômicos de municípios dos vales do Jequitinhonha e Mucuri, abordagem que tem sido utilizada por pesquisadores de vários países. Seguem-se alguns trabalhos cujo enfoque assemelha-se ao proposto nesta pesquisa.

M. E. Leite, Clemente e M. R. Leite (2008) realizaram estudo semelhante na microrregião de Montes Claros-MG. Os autores usaram os indicadores socioeconômicos: índice de Gini, intensidade de pobreza, índice de desenvolvimento humano e intensidade de indigência, representando os resultados em mapas coropléticos, cuja elaboração foi mediada por tecnologias da geoinformação. As características socioeconômicas de áreas residenciais e risco de morte utilizando-se dos parâmetros estatísticos do índice de Moran foram analisadas na Finlândia por Halonen et al., (2013).

Nunes (2013) realizou análise exploratória usando SIG e estatística espacial para identificar agrupamentos de municípios com características socioambientais semelhantes em duas mesorregiões de planejamento de Goiás. Na Rússia, um estudo visando identificar clusters de desigualdades socioespaciais foi realizado por Litvintseva e Stukalenko (2014). Os autores verificaram variação inter-regional do ponto de vista social.

De La Fuente et al. (2013) identificaram segregação socioespacial na Região Metropolitana de Concepción (RMC), Chile. Esses autores identificaram padrões de dependência espacial relativos à falta de acesso a serviços de qualidade nas áreas periféricas da RMC. X. Chen et al. (2015) usaram sistemas de informações georreferenciadas para analisar os padrões espaciais da distribuição da pobreza em áreas rurais de Xianfeng County (China). Esses autores aplicaram métodos e técnicas de geoestatística para explicar essas mazelas sociais no âmbito campesino daquela porção territorial.

$\bigcirc$ objetivo deste trabalho compreende a análise exploratória espacial de dados socioeconômicos de duas mesorregiões de Minas Gerais: os vales do Jequitinhonha e do Mucuri. $\bigcirc$ enfoque principal abrange a distribuição espacial dos indicadores de renda per capita média, razão de dependência demográfica, proporção de extremamente pobres e taxa de envelhecimento populacional, os quais foram submetidos a análise de autocorrelação espacial em nível municipal. 


\section{Análise exploratória de dados espaciais}

A análise exploratória de dados espaciais consiste em verificar a relação entre as entidades geográficas pelo valor de determinado indicador ou de uma amostragem (IDH, precipitação, teor de minerais no solo etc.) e permite verificar a relação existente entre áreas vizinhas. Além disso, mostra se há autocorrelação espacial (Box map) e também sua própria confiabilidade, por meio de um mapa de probabilidade denominado Lisa map (Anselin, 1995; Nunes, 2013; Chen, Y., 2013). No primeiro caso (Box map), apresenta-se uma representação espacial para o diagrama de espalhamento de Moran (Figura 1).

Nesse diagrama, cada quadrante representa um valor que varia de 1 a 4 . Assim, os municípios que apresentam valor igual a 1 ou 2 estão nos quadrantes 1 e $2(\mathrm{Q} 1$ e Q2) e têm correlação positiva entre os valores da variável $(Z)$ normalizada e as médias dos vizinhos (WZ), também normalizadas (Nunes, 2013; Chen, Y., 2013). Nesse caso, o município e seu vizinho têm valores semelhantes da variável estudada. Essa correlação pode ter uma associação espacial em alto-alto (valor positivo e média positiva - Q1) ou baixo-baixo (valor negativo e média negativa Q2) (Câmara et al., 2004; Nunes, 2013; Chen, Y., 2013).

\section{Figura 1 - Diagrama de espalhamento de Moran}

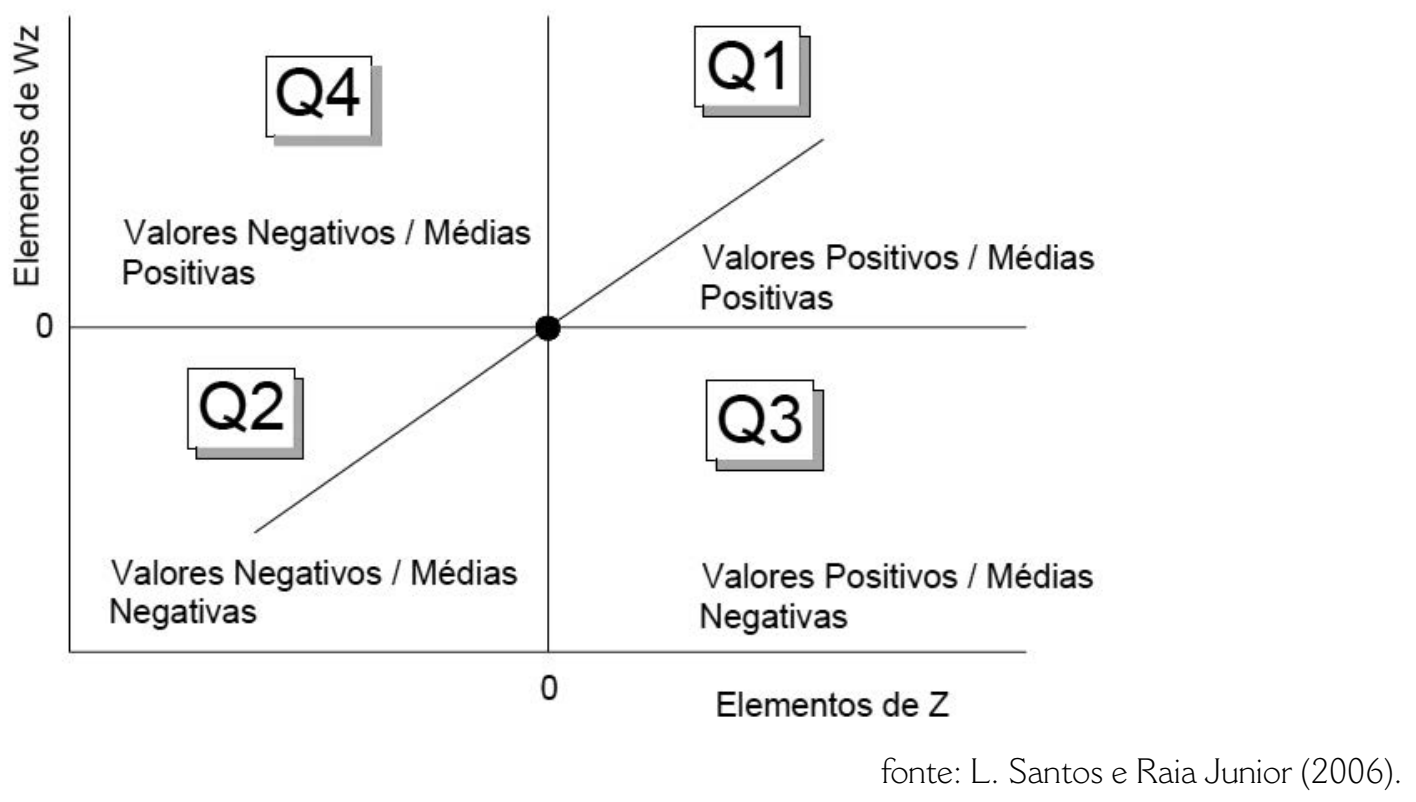

Os valores correspondentes a 3 e 4 (Q3 e Q4) indicam correlação espacial negativa, ou seja, os valores das variáveis de cada local (município) não se relacionam espacialmente com os dos entes federativos vizinhos, o que produz padrões espaciais do tipo alto-baixo (valor positivo e média negativa - Q3) ou baixo-alto (valor negativo e média positiva - Q4) (Santos, L.; Raia Junior, 2006).

Quanto ao Lisa map, é um mapa coroplético gerado a partir do indicador de associação espacial local (Lisa - local indicators of spatial association), que expressa a dependência espacial em nível local. $\bigcirc$ Lisa map apresenta situações de autocorrelação espacial quando esse índice é menor que 0,05 (5\%) (Nunes, 2013). Segundo a autora, o índice Lisa gera um mapa em que 
as áreas são classificadas do seguinte modo: Sem significância; significância de 0,05 (95\% de confiança); de 0,01 (99\% de confiança); de 0,001 (99,9\% de confiança) e de 0,0001 (99,99\% de confiança).

indicador de associação espacial local é um parâmetro estatístico que apresenta valores proporcionais aos da estatística global, de modo que permite descrever o grau de semelhança ou diferença de cada evento em relação com os eventos mais próximos. Logo, a soma total do Lisa de todas as áreas é proporcional ao valor obtido para o índice de Moran global (Anselin, 1995; Nunes, 2013; Chen, Y., 2013).

\section{Material e métodos}

\section{Localização}

Os vales do Jequitinhonha e Mucuri ficam em Minas Gerais e compreendem a porção nordeste (NE) do estado (Figura 2). Essas duas mesorregiões abrangem 74 municípios e, em 2010, tinham 1.002.119 habitantes (Tabela 1).

\section{Tabela 1 - Aspectos demográficos dos vales do Jequitinhonha e Mucuri}

\begin{tabular}{|c|c|c|c|c|}
\hline \multicolumn{5}{|c|}{ população dos vales do Jequitinhonha e Mucuri 2010 } \\
\hline urbana & rural & urbana (\%) & rural (\%) & total \\
\hline 632.867 & 369.252 & 63,15 & 36,85 & 1.002 .119 \\
\hline
\end{tabular}

fonte: Elaboração própria com dados do IBGE e da Fundação João Pinheiro.

Como observado acima, a população dos vales do Jequitinhonha e Mucuri era majoritariamente urbana $(63,15 \%)$. A renda per capita média dessa porção territorial equivalia a $R \$ 431,75$ (em agosto de 2010), ou 84,66\% de um salário-mínimo (IBGE, [201-]). Em valores corrigidos, equivaleria a $R \$ 793,26$ em janeiro de 2017. Por outro lado, esse mesmo índice foi de R \$ 545,00 no estado de Minas Gerais naquele ano (IBGE, [201-]). Os vales do Jequitinhonha e Mucuri ocupam $70.223 \mathrm{~km}^{2}$, o que resulta uma densidade demográfica baixa $(14,27)$, mas o estado de Minas Gerais apresenta uma densidade em torno de 35,8 habitantes por $\mathrm{km}^{2}$ (IBGE, [201-]). 
Figura 2 - Municípios dos vales do Jequitinhonha e Mucuri $45^{\circ} \mathrm{W}$

$42^{\circ} \mathrm{W}$

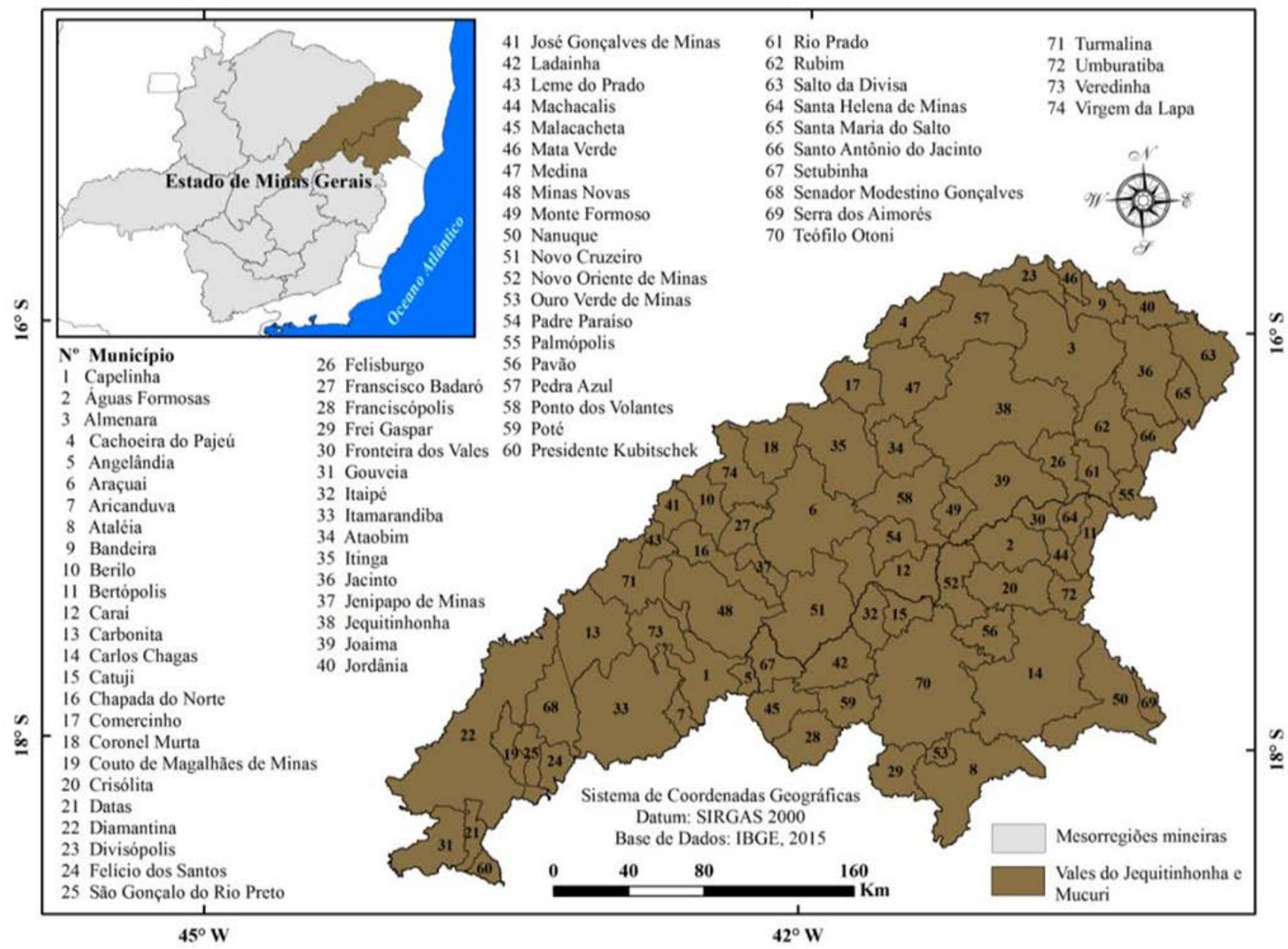

fonte: Elaboração própria.

\section{Procedimentos metodológicos}

Os procedimentos metodológicos obedeceram as seguintes etapas: (I) pesquisa bibliográfica e obtenção de dados secundários, (II) aplicação de análise exploratória por meio da estatística espacial e (III)- elaboração de mapas temáticos.

\section{Pesquisa bibliográfica e obtenção de dados secundários}

Nessa fase, consultaram-se teses, dissertações, artigos científicos e livros cujo tema se relaciona com o objetivo desta investigação. Ademais, sites como o IBGE cidades, Instituto Brasileiro de Geografia e Estatística (IBGE), Programa das Nações Unidas para o Desenvolvimento (Pnud), Instituto de Pesquisa Econômica Aplicada (Ipea) e o aplicativo do Atlas de Desenvolvimento Humano de 2013 serviram de base para a obtenção de dados secundários.

Numa delimitação temporal, foram coletados dados de 1991, 2000 e 2010. Destes, foram selecionados quatro indicadores socioeconômicos (Tabela 2). 


\section{Aplicação de análise exploratória por meio de estatística espacial}

Os dados foram submetidos a tratamento estatístico com objetivo de identificar dependência espacial entre os municípios dos vales do Jequitinhonha e Mucuri. Aplicaram-se os índices de Moran global e local, que permitiram identificar áreas com forte, média ou baixa dependência espacial.

\section{Tabela 2 - Informações sobre os indicadores socioeconômicos}

\begin{tabular}{|l|l|l|}
\hline \multicolumn{1}{|c|}{ sigla } & \multicolumn{1}{|c|}{ nome } & \multicolumn{1}{c|}{ definição } \\
\hline RDPC & $\begin{array}{l}\text { renda per capita } \\
\text { média }\end{array}$ & $\begin{array}{l}\text { razão entre o somatório da renda de todos os indivíduos residentes em } \\
\text { domicílios particulares permanentes e o número total desses indivíduos } \\
\text { (em reais de } 1 \text { ago. 2010) }\end{array}$ \\
\hline RAZDEP & $\begin{array}{l}\text { razão de dependência } \\
\text { demográfica }\end{array}$ & $\begin{array}{l}\text { razão de dependência é medida pela razão entre o número de pessoas } \\
\text { com } 14 \text { anos ou menos e com } 65 \text { anos ou mais de idade (população } \\
\text { dependente) e o número de pessoas com idade de } 15 \text { a } 64 \text { anos } \\
\text { (população potencialmente ativa), multiplicada por } 100\end{array}$ \\
\hline PIND & $\begin{array}{l}\text { proporção de } \\
\text { extremamente pobres }\end{array}$ & $\begin{array}{l}\text { proporção dos indivíduos com renda domiciliar per capita igual ou } \\
\text { inferior a } R \$ 70,00 \text { mensais (em reais de ago. 2010) (o universo de } \\
\text { indivíduos é limitado àqueles que vivem em domicilios particulares } \\
\text { permanentes) }\end{array}$ \\
\hline TENV & $\begin{array}{l}\text { taxa de } \\
\text { envelhecimento } \\
\text { populacional }\end{array}$ & $\begin{array}{l}\text { razão entre a população de } 65 \text { anos ou mais de idade e a população } \\
\text { total, multiplicada por } 100\end{array}$ \\
\hline
\end{tabular}

fonte: Pnud, Ipea e FJP (2013).

Além disso, possibilitaram identificação de regiões em que não há autocorrelação espacial estatisticamente significativa (Anselin, 1995; Silva, A. B., 2003; Câmara et al., 2004; Oliveira, 2012; Nunes, 2013; Chen, Y., 2013). A equação do índice de Moran global (equação 1) é a seguinte:

$$
I=\frac{n}{\sum \sum w_{i j}} \frac{\sum \sum w_{i j}\left(y_{i}-\bar{y}\right)\left(y_{j}-\bar{y}\right)}{\sum\left(y_{j}-\bar{y}\right)^{2}}
$$

$\mathrm{y}_{\mathrm{i}}=$ valor da variável y na região $\mathrm{i}$

$\mathrm{y}_{\mathrm{j}}=$ valor da variável y na região $j$

$\overline{\mathbf{y}}=$ média de $\mathrm{y}$

$\mathrm{w}_{\mathrm{ij}}=$ elemento ij da matriz de proximidade espacial

$\mathrm{n}=$ número de observações

Esse procedimento é útil para indicar a autocorrelação entre municípios vizinhos e oferece os agrupamentos (quando existentes) de modo a orientar decisões mais cautelosas pelo poder público (Oliveira, 2012; Nunes, 2013). Para aplicar esses procedimentos, é necessária uma matriz de proximidade espacial que apresenta o peso de cada situação, sendo vizinho $=1$, e não vizinho = 0 (Anselin, 1995; Oliveira, 2012; Nunes, 2013; Chen, Y., 2013). 
O indicador Lisa é uma decomposição do índice de Moran global. Permite a construção de um mapa de dependência espacial local, portanto, dá mais detalhes que o indicador global (Anselin, 1995; Silva, A. B., 2003; Câmara et al., 2004). A equação 2 expressa o índice de Moran local.

$$
I i=\frac{\sum w_{i j} z_{i} z_{j}}{\sum_{i=1}^{n} z_{i}^{2}}
$$

$I_{i}=$ índice local de Moran

$Z_{i}=$ diferença entre o valor do atributo no local e a média de todos os atributos

$Z_{\mathrm{j}}=$ diferença entre o valor do atributo no local e a média de todos os atributos

$\mathrm{w}_{\mathrm{ij}}=$ pesos ou graus de conectividade atribuídos conforme a relação topológica entre as i e j

O índice de Moran foi calculado com 99 permutações, com o aplicativo TerraView 4.2.2 $2^{\mathrm{TM}}$.

\section{Elaboração de mapas temáticos}

Nesta etapa, foram elaboradas duas classes de mapas coropléticos: das variáveis socioeconômicas e do índice de Moran dessas variáveis. Estes últimos representam os resultados das análises para os quatro indicadores socioeconômicos. Em cada conjunto de mapas, observou-se a existência ou não de clusters entre os municípios. Os nomes atribuídos aos mapas são Box map e Lisa map (Anselin, 1995; Oliveira, 2012; Nunes, 2013).

Os aplicativos utilizados foram: GeoDa 1.8.10 ${ }^{\mathrm{TM}}$, TerraView 4.2.2 ${ }^{\mathrm{TM}}$ e ArcGIS 9.3 ${ }^{\mathrm{TM}}$. Os dois primeiros serviram como suporte principal para o procedimento geoestatístico, isto é, para a análise exploratória dos dados. O último (ArcGIS 9.3 ${ }^{\mathrm{TM}}$ ) foi utilizado para elaboração dos layouts finais, bem como para a criação e edição de material elementar para os procedimentos necessários.

A opção pela escala de análise por município ocorreu devido ser este o nível em que as políticas públicas (estaduais ou federais) surtem efeitos. Assim, considera-se neste trabalho que é no âmbito municipal que as decisões políticas tomam corpo e têm consequências, positivas ou não (Lindblon, 1991). Portanto, a autocorrelação espacial entre entes federativos pode indicar situações correlatas entre municípios que poderão ser corrigidas ou atenuadas por meio de criação de cooperativa municipal, como já ocorre, nesse caso, com o eixo da saúde. Tendo em vista o uso de duas mesorregiões delimitadas pelo IBGE com critérios predeterminados, neste trabalho não foi considerado o efeito de borda nos resultados.

\section{Resultados e discussão}

Os municípios dos vales do Jequitinhonha e Mucuri são marcados por desigualdades socioeconômicas. Um estudo realizado na microrregião de Diamantina sugere a necessidade de novas políticas públicas visando a equidade entre os entes federativos desta porção territorial (Fonseca et al., 2016; Fonseca, Silva, A. C.; Senna, 2018). O mapa de renda per capita média (Figura 3) 
sustenta os mesmos resultados apontados por Fonseca et al. (2016), pois, se observa a concentração de renda em determinados municípios (Diamantina, Teófilo Otoni e Nanuque), sobretudo em 2010.

Para a razão de dependência demográfica, importante indicador populacional, se observa uma concentração entre os municípios centrais das mesorregiões em estudo (principalmente Minas Novas, Chapada do Norte, Novo Cruzeiro e Setubinha). Embora esse indicador tenha sido baixo entre 1991 e 2010, o de Setubinha permaneceu com os maiores valores, enquanto o dos demais municípios foi reduzido (Figura 4).

Figura 3 - Razão de dependência - renda per capita média nos vales do Jequitinhonha e Mucuri - 1991, 2000, 2010
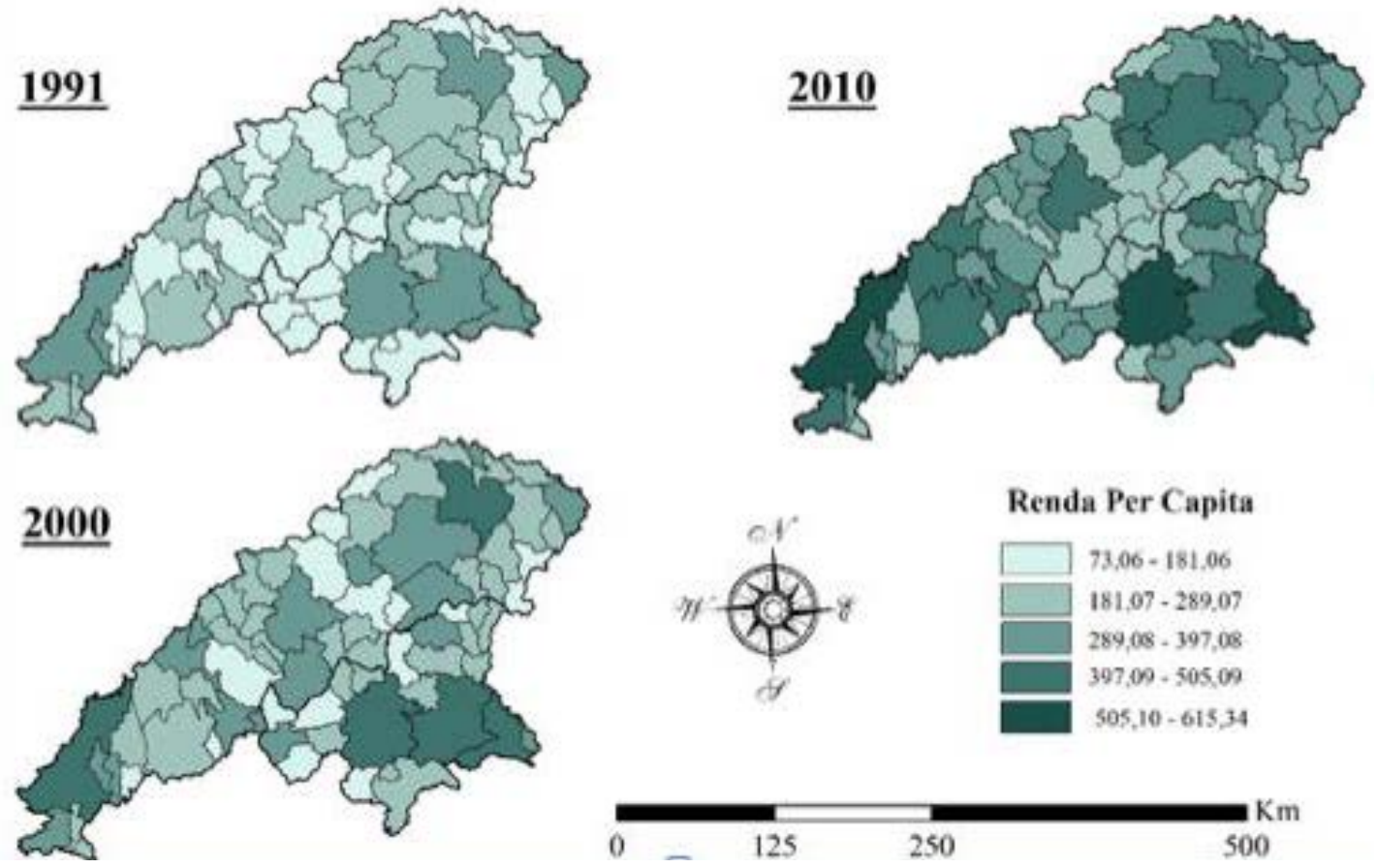

fonte: Elaboração própria. 

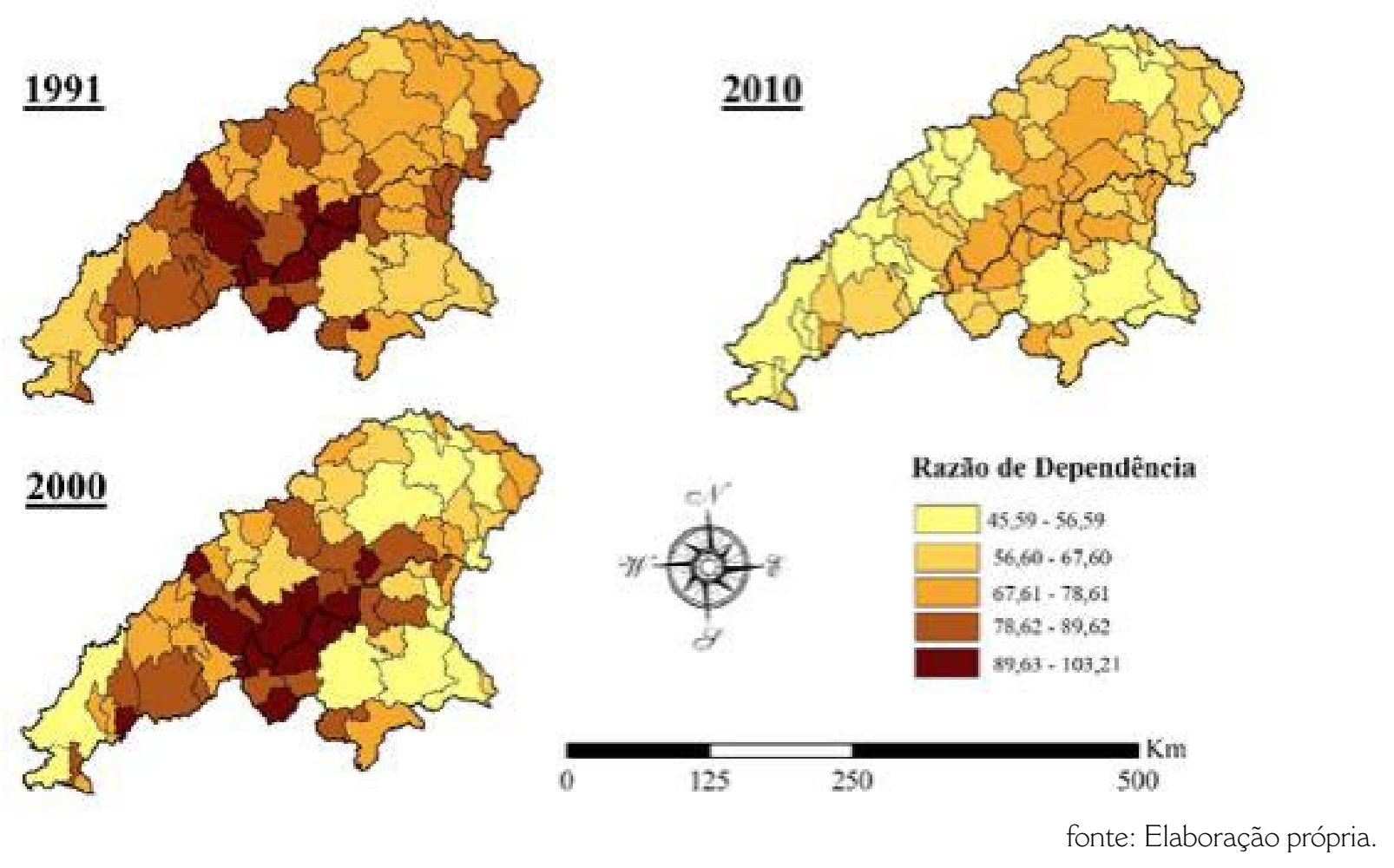

No que diz respeito a proporção de extremamente pobres, nota-se que esse indicador estava relativamente concentrado na porção central da área de estudo. Em 1991 o índice estava distribuído esparsamente entre os entes federativos da área pesquisada (Felício dos Santos a SW, Novo Cruzeiro na área central e Bandeira a NE). Entretanto, nota-se que este índice foi reduzido pela metade no período estudado (o valor máximo foi de 69,22 em 1991, reduzido para 32,25 em 2010), resultado que exprime um fator positivo (Figura 5).

Diamantina, Teófilo Otoni e Nanuque (maior renda per capita média) correspondem aos municípios que apresentam menor proporção de extremamente pobres. Esse fenômeno pode estar relacionado, entre outros fatores, à implantação da Universidade Federal dos Vales do Jequitinhonha e Mucuri (UFVJM) nesses entes federativos, exceto em Nanuque (Fonseca et al., 2016).

A taxa de envelhecimento populacional permaneceu em ascensão entre 1991 e 2010 em todos os municípios da área pesquisada (Figura 6). Portanto a área estudada está dentro da tendência de envelhecimento populacional, que ocorre a passos largos no Brasil e no mundo (Baldoni; Pereira, 2011; Küchemann, 2012). 
Figura 5 - Proporção de extremamente pobres nos vales do Jequitinhonha e Mucuri - 1991, 2000, 2010
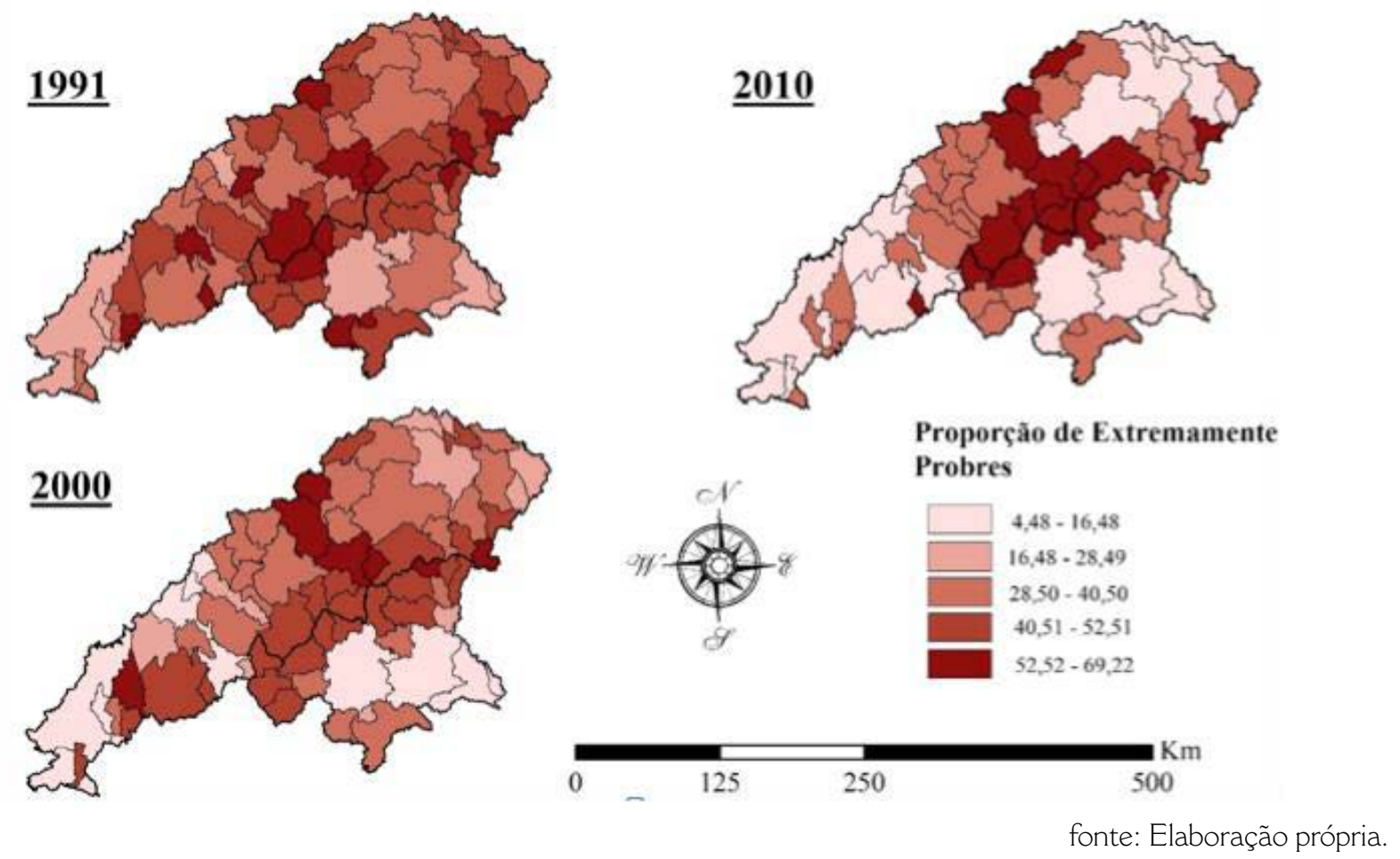

Figura 6 - Taxa de envelhecimento populacional nos vales do Jequitinhonha e Mucuri - 1991, 2000, 2010
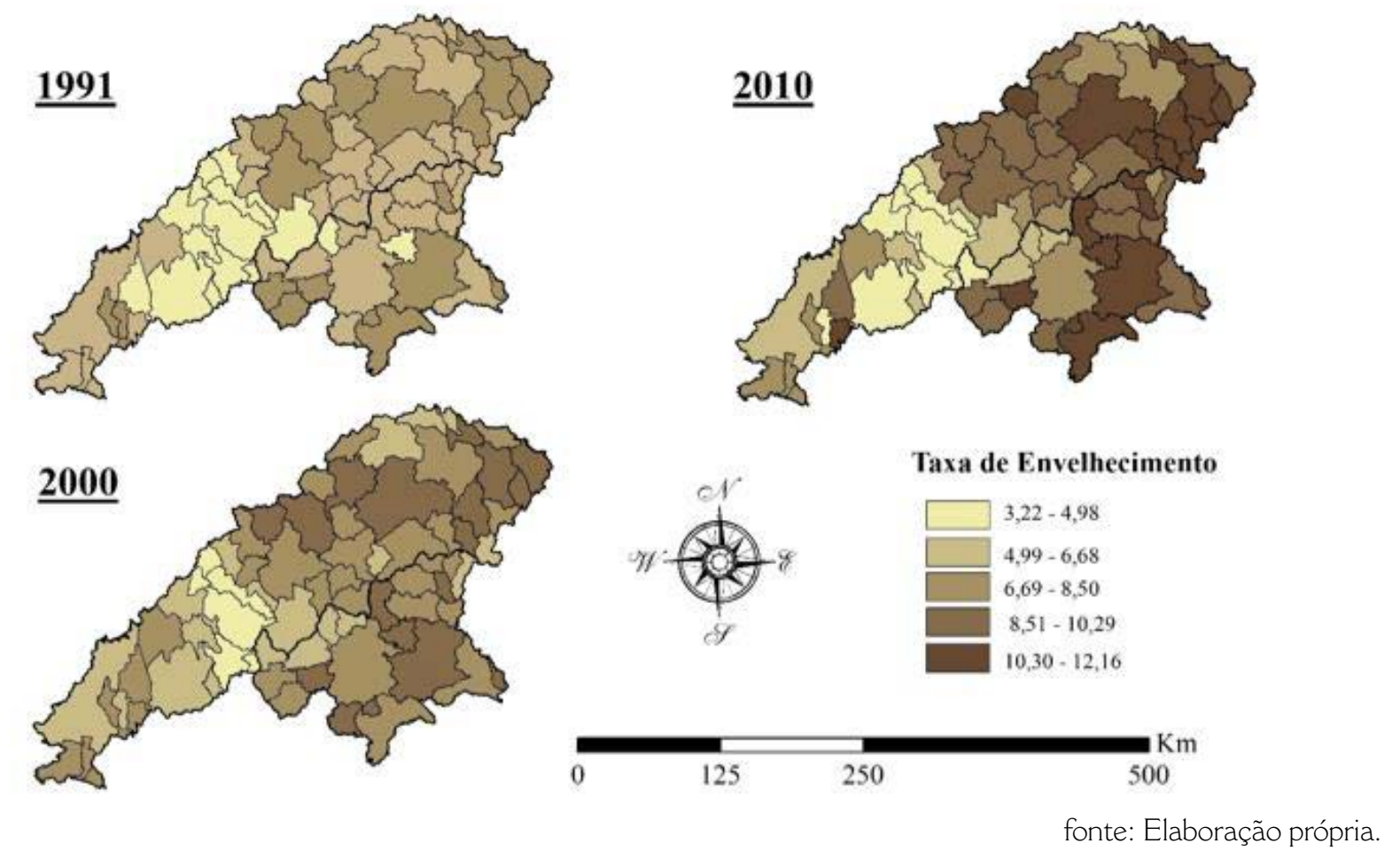
Cabe destacar que os municípios centrais (Minas Novas, Chapada do Norte e Capelinha) apresentaram os menores valores para esse indicador. Por outro lado, Carlos Chagas e Jequitinhonha apresentaram as maiores taxas de envelhecimento no período estudado. Esse fato indica a necessidade de investigações mais profundas sobre as causas e consequências dessa situação para os referidos municípios, posto que a transição demográfica implica novas demandas e necessidades sociais que exigem reorientação de políticas públicas (Baldoni; Pereira, 2011; Küchemann, 2012).

\section{Índice de Moran global}

Os valores para o índice de Moran global demonstram a ocorrência de autocorrelação espacial positiva para os indicadores socioeconômicos e demográficos analisados (Tabela 2). Cabe destacar que a variável renda per capita média tem valores de Moran muito baixos em 1991 e 2010, além de um nível de significância > 0,05 (p-valores) neste período, de modo a não conceber a hipótese da autocorrelação espacial. Fator justificado pela desigualdade na distribuição de renda na área pesquisada.

\section{Tabela 3 - Teste de autocorrelação espacial - índice de Moran}

\begin{tabular}{|c|c|c|c|}
\hline ano & indicador socioeconômico & índice de Moran global & p-valor \\
\hline \multirow{4}{*}{ ळ } & razão de dependência demográfica & 0,3160 & 0,02 \\
\hline & renda per capita média & 0,1018 & 0,12 \\
\hline & proporção de extremamente pobres & 0,2145 & 0,03 \\
\hline & taxa de envelhecimento populacional & 0,4917 & 0,01 \\
\hline \multirow{4}{*}{ 옹 } & razão de dependência demográfica & 0,3472 & 0,01 \\
\hline & renda per capita média & 0,1133 & 0,05 \\
\hline & proporção de extremamente pobres & 0,2927 & 0,01 \\
\hline & taxa de envelhecimento populacional & 0,5601 & 0,01 \\
\hline \multirow{4}{*}{$\stackrel{\circ}{\text { 유 }}$} & razão de dependência demográfica & 0,4174 & 0,01 \\
\hline & renda per capita média & 0,1198 & 0,09 \\
\hline & proporção de extremamente pobres & 0,3145 & 0,01 \\
\hline & taxa de envelhecimento populacional & 0,6231 & 0,01 \\
\hline
\end{tabular}

fonte: Elaboração própria.

No ano 2000, a mesma variável citada tem significância aceitável (0,05), mas o valor do índice de Moran foi muito baixo $(0,1133)$. A taxa de envelhecimento populacional apresentou os maiores valores para o índice de Moran global além de nível de significância aceitável $(0,01)$ em todo o período estudado. Esse fato indica dependência espacial entre os municípios nesse indicador. Portanto, pode-se afirmar que o envelhecimento da população é um fenômeno comum entre dois ou mais entes federativos vizinhos na área estudada.

A razão de dependência demográfica manteve-se com valor de Moran global abaixo da taxa de envelhecimento populacional, porém superior aos demais indicadores. Tanto em 1991 $(0,3160)$ quanto em $2000(0,3472)$ e $2010(0,4174)$, essa variável mostrou dependência espacial. 
Além disso, manteve nível de significância aceitável (entre 0,01 e 0,02). Esse resultado pode ter origem nos altos níveis de desemprego, que são comuns nos municípios da área de pesquisa.

\section{Indicador de associação espacial local (Lisa)}

$\bigcirc$ índice de Moran local possibilitou identificar agrupamentos de variáveis socioeconômicas entre os municípios da área pesquisada nos anos 1991, 2000 e 2010. Nos mapas temáticos oriundos do Lisa para as variáveis estudadas, estão expressos: o nível de significância da associação espacial (Lisa map) e o mapa do diagrama de espalhamento de Moran (Box map) (Figura 7).

Embora o índice de Moran global não tenha sido estatisticamente significativo para renda per capita média, o indicador local permitiu verificar clusters de concentração de renda, principalmente no vale do Mucuri (entre Carlos Chagas e Nanuque, na porção SE da área estudada). $\bigcirc$ Box map confirma a autocorrelação espacial entre esses municípios, pois situam-se no quadrante 1-Q1 (alto-alto), de modo que apresentam valores superiores à média (desvios positivos) e seus vizinhos apresentam valores correlatos. Portanto, formam um cluster positivo (municípios vizinhos com concentração de renda). Além disso, o Lisa map destaca estes municípios com elevado grau de confiança (entre 95 e 99,9\%). Ou seja, pode-se afirmar com 95\% e mesmo 99,9\% de certeza que esses municípios têm dependência espacial.

A maioria dos territórios da porção central (Francisco Badaró, Jenipapo de Minas, Novo Cruzeiro) está inserida no Q2 (baixo-baixo). Isto é, apontam autocorrelação de valores negativos. Baixos valores de renda per capita e média dos municípios vizinhos em situação semelhante. Durante o período analisado, houve pouca variação no quadrante 2, o que sugere dificuldade dos municípios quanto ao crescimento econômico. Araçuaí (área central), situado no Q3 (alto-baixo), apresenta média elevada, ao contrário de seus vizinhos, na variável analisada. Ou seja, é um município com altos valores de renda em meio a entes federativos em situação inferior, resultado que confirma desigualdades socioespaciais nos vales do Jequitinhonha e Mucuri.

A razão de dependência demográfica apresentou associação espacial local nas mesmas áreas entre 1991 e 2010 (Figura 8). Nota-se que a variação entre as áreas de dependência espacial positiva (Q1) foi baixa no período estudado. Municípios situados na divisa entre os vales (Jequitinhonha/Mucuri) mostraram dependência espacial nesse indicador, de modo que esses territórios apresentam semelhanças. Minas Novas e Capelinha apresentaram autocorrelação positiva com nível de significância de 0,001 (99,9\% de confiança) entre 1991 e 2000. 
Figura 7 - Lisa map e Box map - autocorrelação espacial para renda per capita média nos vales do Jequitinhonha e Mucuri

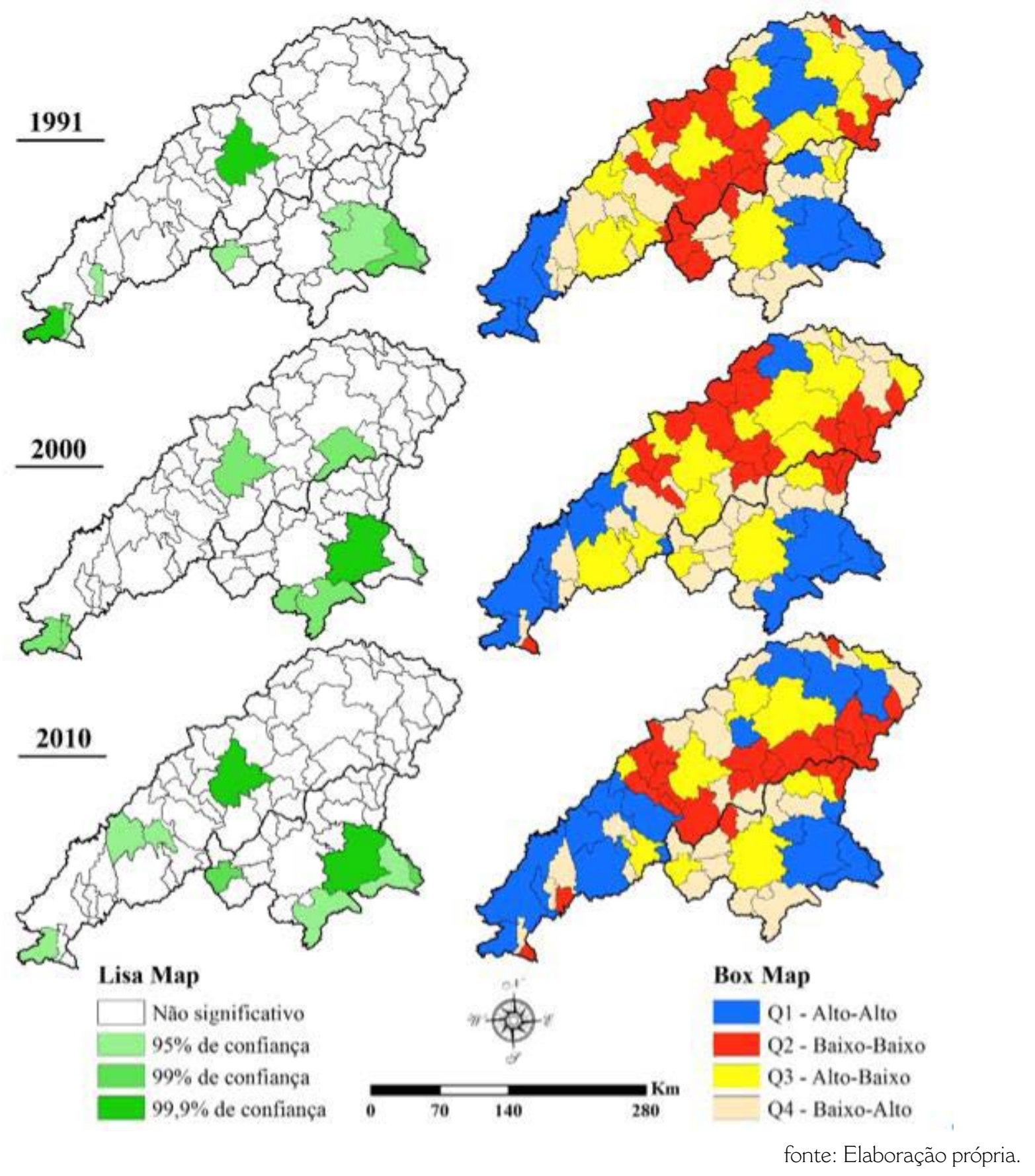

Em 2010, esses dois municípios não demonstraram autocorrelação positiva. Novo Cruzeiro e Ladainha (divisa entre os vales) apresentaram dependência espacial em todo o período analisado, com valores $\geq 95 \%$ confiança. Portanto, os territórios dessa porção (no sentido Centro/NE) necessitam de estudos mais detalhados para verificar as causas do aumento da variável sociodemográfica em questão. Esses resultados podem estar associados a migrações da população em idade ativa na busca de oportunidades de trabalho em outras regiões, dadas as características dos vales. Nesses termos, políticas públicas de geração e distribuição de renda devem ser elaboradas nas referidas mesorregiões para reduzir essa migração. 
Figura 8 - Lisa map e Box map - autocorrelação para razão de dependência demográfica nos vales do Jequitinhonha e Mucuri

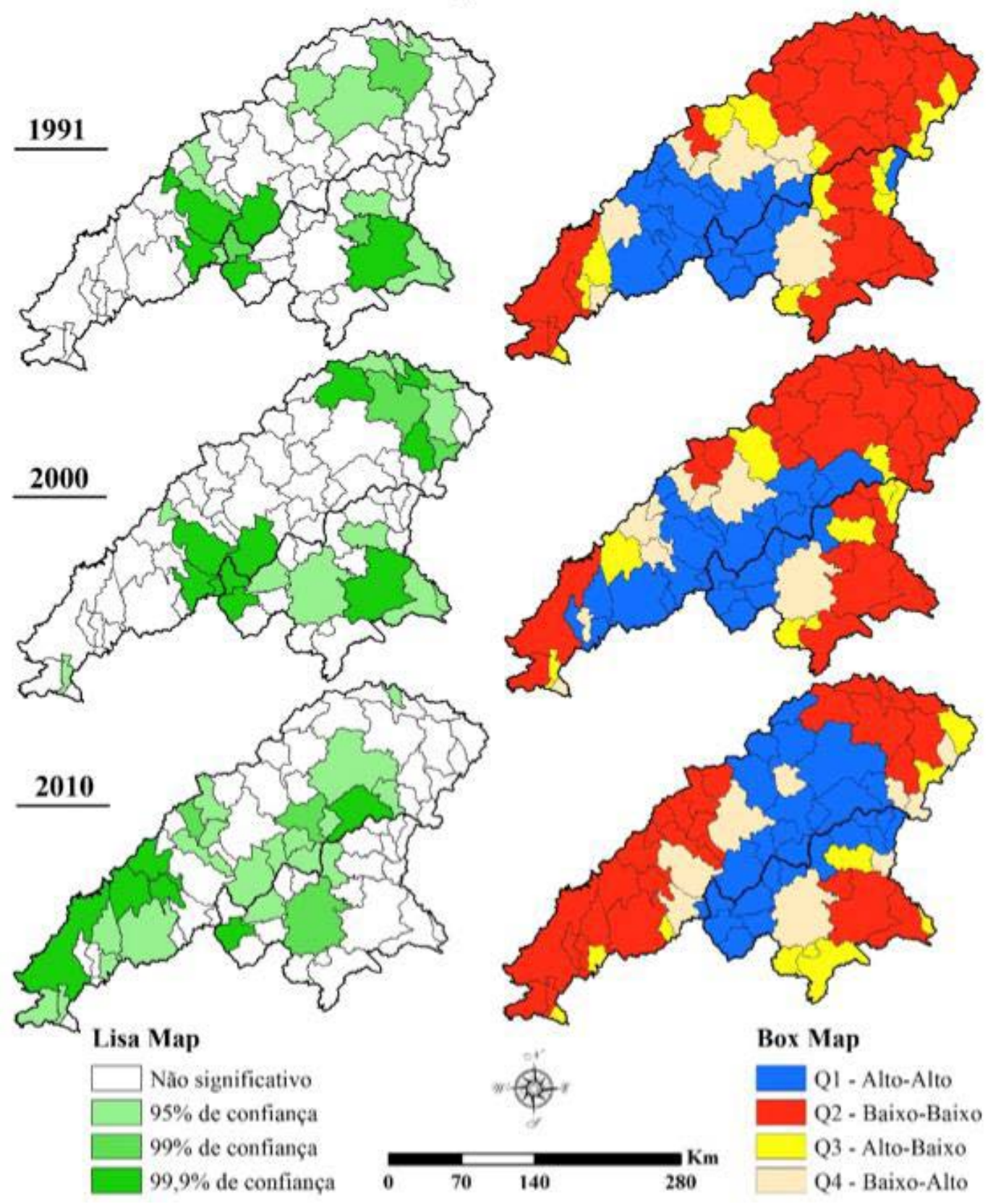

fonte: Elaboração própria.

Por outro lado, municípios como Diamantina, Gouveia, Felício dos Santos (SW- significativo para 2010), Carlos Chagas e Nanuque (SE - significativos para 1991 e 2000) e Jequitinhonha, Almenara e Divisópolis (entre outros a NE - significativos para 1991 e 2000) demonstraram autocorrelação espacial positiva (Q2) quanto a baixos valores da razão de dependência. Esse é um fator positivo, pois quanto menor o valor dessa variável maior interação econômica no município. 
Figura 9 - Lisa map e Box map - autocorrelação espacial para proporção de extremamente pobres nos vales do Jequitinhonha e Mucuri

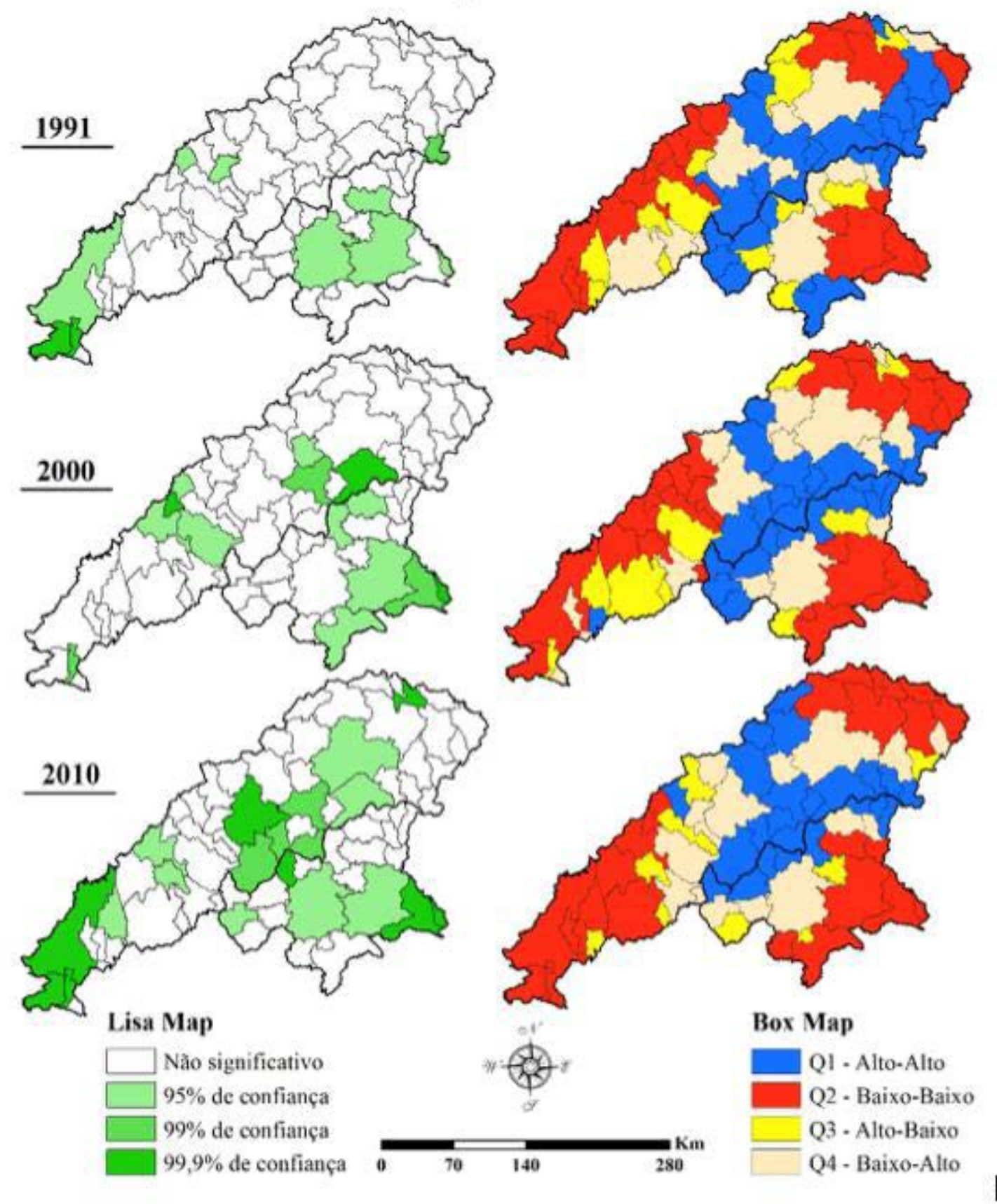

fonte: Elaboração própria.

No que diz respeito à proporção de extremamente pobres (Figura 9), Palmópolis apresenta dependência espacial (significância de 0,01) para 1991 e não significativo para 2000 e 2010. Joaíma e Ponto dos Volantes (divisa entre os vales) demonstraram autocorrelação positiva (Q1) em 2000 e 2010 e foram significativos (95 e 99,9\% de confiança). Diamantina, Carlos Chagas, Nanuque, Serra dos Aimorés situaram entre os municípios com autocorrelação espacial positiva para os menores valores (Q2) da variável em estudo de modo satisfatório ( $\geq 95 \%$ de confiança) para 1991 e 2010. 
Em 2010 ocorreram alterações no que concerne a significância da análise. Observa-se que os municípios situados nos quadrantes de autocorrelação espacial positiva (Q1 e Q2) permaneceram os mesmos (com algumas exceções), todavia houve aumento da significância para outros entes federativos. Novo Cruzeiro, Caraí, Itaipé foram adicionados a Joaíma e Ponto dos Volantes como áreas de dependência espacial para a proporção de extremamente pobres. Estes resultados realçam a necessidade de políticas públicas orientadas ao nivelamento socioeconômico nos vales do Jequitinhonha e Mucuri, principalmente nos municípios situados na divisa entre os vales. Além disso, proposições de desenvolvimento endógeno (de dentro) devem ser pensadas peras os municípios em situações críticas, visando geração de renda para aplacar a proporção de extremamente pobres.

A variável taxa de envelhecimento populacional, ao contrário das demais analisadas nesta pesquisa cresceu em teor e também na dependência espacial (Figura 10). Os resultados apontam uma separação abrupta entre municípios situados nos quadrantes 1 e 2 (Q1 e Q2) do diagrama de espalhamento de Moran. Entretanto, a autocorrelação espacial local não se mostrou significativa em territórios situados nas porções: central e SW da área de estudo (exceto para Comercinho e Itinga - 1991 e Ataobim - 1991 e 2000).

Esses resultados indicam o enquadramento dos municípios estudados no novo paradigma demográfico mundial, o qual aponta novas demandas da população das faixas etárias mais avançadas (Baldoni; Pereira, 2011; Küchemann, 2012). Assim, os territórios situados em áreas de agrupamentos de envelhecimento populacional precisam ser mais bem compreendidos do ponto de vista sociodemográfico, para que políticas públicas, tanto do eixo da saúde quanto do viés social, sejam implantadas com vistas ao bem-estar dessa parcela da população ((Baldoni; Pereira, 2011).

Municípios situados a NE (Almenara e Salto da Divisa em todo o período, Jequitinhonha em 2010, entre outros) apresentaram dependência espacial positiva (Q1) para taxa de envelhecimento. Na porção SE, destacam-se Nanuque, Ataleia (1991 e 2000) e próximo a divisa dos vales, Franciscópolis (em todo o período analisado) demonstraram situação de dependência positiva (Q1) para o envelhecimento populacional. Entre os territórios com autocorrelação espacial local positiva, para menores taxas de envelhecimento (Q2) se destacam aqueles da porção central/SW (Minas Novas, Turmalina, Capelinha e Carbonita, entre outros), que apresentam nível de significância aceitável $(\leq 0,05)$. 
Figura 10 - Lisa map e Box map - autocorrelação espacial para taxa de envelhecimento populacional nos vales do Jequitinhonha e Mucuri

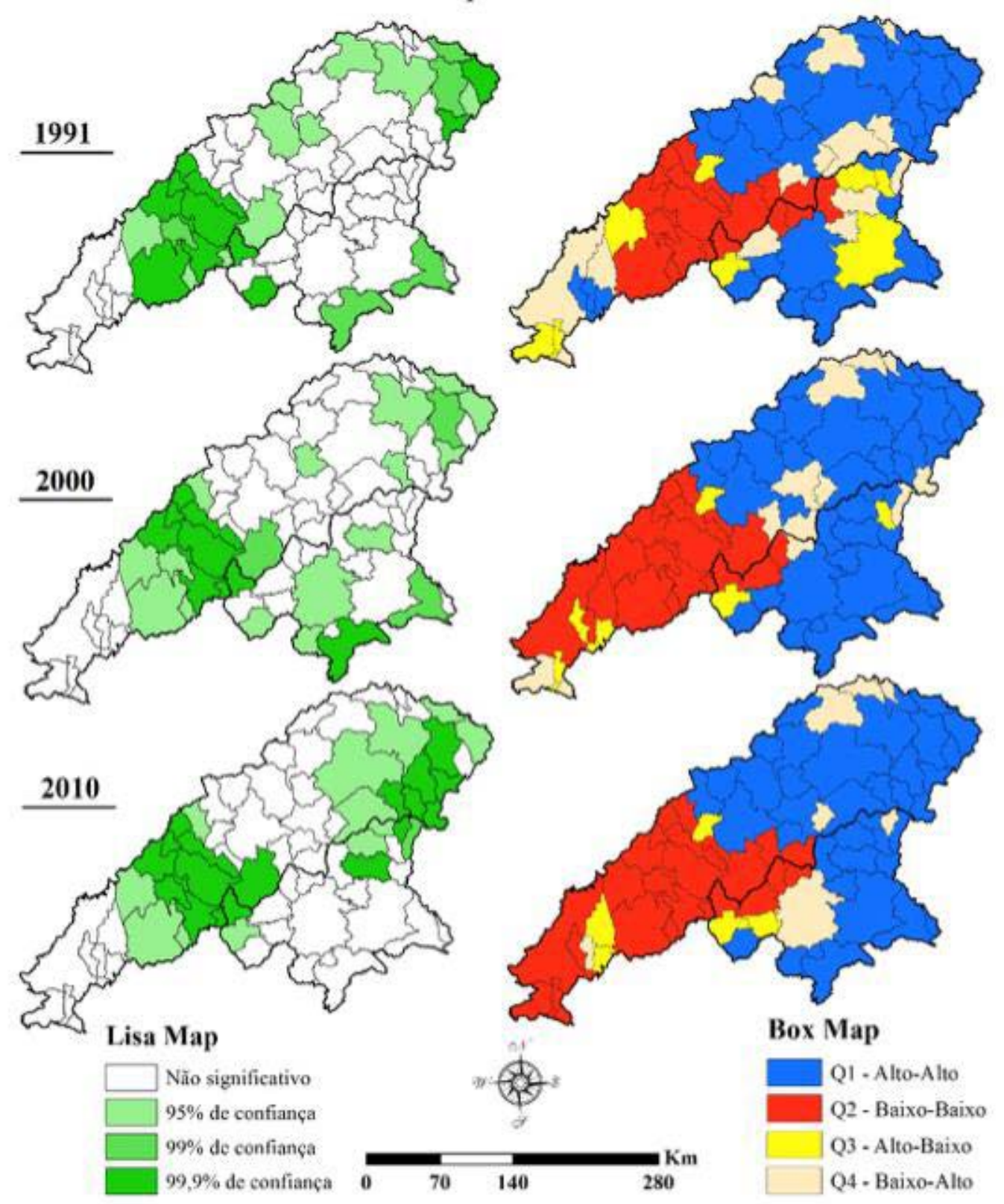

fonte: Elaboração própria.

\section{Considerações finais}

Foi detectada autocorrelação espacial de concentração de renda entre Carlos Chagas e Nanuque na porção SE da área de estudo. Embora os maiores valores de renda per capita média estejam concentrados entre Diamantina e Teófilo Otoni, esses municípios não mostraram correlação espacial com áreas vizinhas. Em 1991, a distribuição espacial da renda per capita abrangia, além dos entes federativos mencionados, Almenara e Salto da Divisa. Isso indica mudança na dinâmica econômica dos vales do Jequitinhonha e Mucuri nas últimas duas décadas.

A razão de dependência foi reduzida entre 1991 e 2010. Entretanto, a distribuição espacial de agrupamentos permaneceu constante nas áreas da divisa dos vales (Jequitinhonha/ Mucuri). Isso indica a necessidade de pesquisas locais com vistas a identificar eventuais efeitos 
socioeconômicos dessa situação. Novo Cruzeiro, Caraí, Itaipé, Joaíma e Ponto dos Volantes foram identificados como áreas de agrupamento na proporção de extremamente pobres. Esses municípios merecem atenção especial, pois o resultado de dependência espacial entre eles acentuou-se em 2010, fator que sugere recessão econômica ou aumento da concentração de renda em relação a 1991 e 2000.

envelhecimento da população dos vales do Jequitinhonha e Mucuri segue a tendência global. Detectou-se autocorrelação espacial entre entes federativos das porções $N E$, SE e divisa dos vales (Q1) e na porção central e NW (Q2). Esse resultado sugere mais atenção à população desses municípios, posto que a transição demográfica em curso exige a adaptação dos sistemas de saúde (principalmente) e de outros setores sociais a esses indivíduos e suas peculiaridades.

A abordagem de autocorrelação espacial permitiu ver um movimento constante nas áreas socialmente vulneráveis nos vales do Jequitinhonha e Mucuri. Tanto os valores do índice de Moran global quanto a análise de associação espacial local permitiram identificar possíveis tendências das variáveis socioeconômicas apresentadas, uma vez que a métrica global mostrou a autocorrelação entre os 74 entes federativos analisados e a abordagem local, a relação de dependência espacial entre os pares municipais.

Novas pesquisas, com enfoque regionalizado, devem suprir as lacunas deste estudo. Portanto, sugere-se que se façam amostragens nos municípios em situação crítica (quanto aos indicadores mencionados aqui), para confirmar ou rejeitar as conclusões a que chegou este trabalho. Nesse caso, devem-se considerar os microdados disponibilizados pelo IBGE em escala de setor censitário. Todavia, em municípios muito pequenos, os setores são, em geral, muito heterogêneos, o que aumenta a necessidade de pesquisa de campo.

\section{Referências}

ANSELIN, L. Local Indicators of Spatial Association-LISA. Geographical Analysis, Ohio State University Press, v. 27, n. 2, p. 93-115, Apr. 1995. doi: https://doi. org/10.1111/j.1538-4632.1995.tb00338.x.

BALDONI, A. O.; PEREIRA, L. R. L. O impacto do envelhecimento populacional brasileiro para o sistema de saúde sob a óptica da farmacoepidemiologia: uma revisão narrativa.

Revista de Ciências Farmacêuticas Básica e Aplicada, v. 32, p. 313-321, 2011.

BUZAI, G. D. Geografía automatizada, ciencias de la información geográfica y ciencias sociales integradas espacialmente: avances cuantitativos para los estudios territoriales del siglo XXI. Fronteras, Buenos Aires, v. 4, n. 4, p. 31-36, 2005.

CÂMARA, G.; CARVALHO, M. S.; CRUZ, O. G.; CORREA, V. Análise espacial de áreas. In: DRUCK, S.; CARVALHO, M. S.; CÂMARA, G.; MONTEIRO, A. V. M. (Ed.). Análise espacial de dados geográficos. Brasilia: Embrapa, 2004. Disponível em: http://www.dpi.inpe.br/gilberto/livro/analise/cap5-areas.pdf. Acesso em: 4 out. 2019.

CHEN, X.; PEI, Z. Y.; CHEN, A. L.; WANG. F.; SHEN, K.; ZOU, Q.; SUN, L. Spatial distribution patterns and influencing factors of poverty - a case study on key country from 
national contiguous special poverty-stricken areas in China. Procedia Environmental Sciences, n. 26, p. 82-90, 2015. doi:10.1016/j.proenv.2015.05.005.

CHEN, Y. New Approaches for Calculating Moran's Index of Spatial Autocorrelation. PLoS ONE, v. 8, n. 7. 12 July 2013. doi: https://doi.org/10.1371/journal.pone.0068336.

DE LA FUENTE, H.; ROJAS, C.; SAlADO, M. J.; CARRASCO, J. A.; NEUTENS, T. Socio-Spatial Inequality in Education Facilities in the Concepción Metropolitan Area (Chile). Current Urban Studies, v. 1, n. 4, p. 117-129, 2013.

FONSECA, S. F; HERMANO, V. M.; SILVA, A. C. Mapeamento do uso da terra nos municípios de Janaúba e Nova Porteirinha (MG) usando dados de sensoriamento remoto. Élisée - Revista de Geografia da UEG, v. 5, p. 103-119, 2016.

FONSECA, S. F; MENDONCA, G. L.; HERMANO, V. M.; SILVA, A. C. Análise da pobreza e desenvolvimento humano na microrregião de Diamantina/MG, Brasil, usando técnicas de geoprocessamento. Revista Geográfica Acadêmica, v. 10, p. 164-179, 2016.

FONSECA, S. F; SANTOS, D. C.; HERMANO, V. M. Geoprocessamento aplicado à análise dos impactos socioambientais urbanos: estudo de caso do Bairro Santo Expedito em Buritizeiro/MG. Revista de Geografia, Recife, v. 30, n. 3, p. 178-191, 2013.

FONSECA, S. F; SANTOS, D. C.; TRINDADE, W. M. Técnicas de geoprocessamento aplicadas na classificação e avaliação da distribuição das espécies arbóreas nas praças de Buritizeiro/MG. Geografia Ensino E Pesquisa, Santa Maria, v. 18, n. 2, p. 109-122, 2014.

FONSECA, S. F; SILVA, A. C.; SENNA, J. A. Técnicas de geoprocessamento aplicadas na identificação de usos da terra no entorno das turfeiras da Serra do Espinhaço Meridional. RA'EGA - Espaço Geográfico em Análise, v. 43, p. 124-139, 2018.

HALONEN, J. I.; VAHTERA, J.; OKSANEN, T.; PENTTI, J.; VIRTANEN, M.; JOKELA, M.; DIEZ-ROUX, A. V.; KIVIMÄKI, 3. Socioeconomic characteristics of residential areas and risk of death: is variation in spatial units for analysis a source of heterogeneity in observed associations? BMJ Open, v, 3, n. 4, 2013. doi: 10.1136/bmjopen-2012-002474. Print 2013.

IBGE. INSTITUTO BRASILEIRO DE GEOGRAFIA E ESTATÍSTICA. Cidades. [201-]. Disponível em: http://cidades.ibge.gov.br/xtras/perfil.php?lang=E codmun=312160. Acesso em: 31 jul. 2017.

KÜCHEMANN, B. A. Envelhecimento populacional, cuidado e cidadania: velhos dilemas e novos desafios. Sociedade e Estado, v. 27, n. 1, p. 165-180, 2012. DOI: https://dx.doi. org/10.1590/S0102-69922012000100010.

LEITE, M. E.; CLEMENTE, C. M. S.; LEITE, M. R. Sistema de informação geográfica aplicado á análise dos indicadores sociais da microrregião de Montes Claros (MG) - 1991 e 2000. In: COLÓQUIO INTERNACIONAL (DES) ENVOLVIMENTOS CONTRA A POBREZA, 1., 2008, Unimontes, Montes Claros, MG. Anais... Montes Claros, 2008. 
LINDBLON, C. E1 proceso de elaboración de políticas públicas. Madrid: Ministério de Administração Pública, 1991.

LITVINTSEVA, G.; STUKALENKO, E. Differentiation of Population Incomes in Innovative Regions of Russia. Procedia Economics and Finance, v. 16, p. 56-63, 2014.

LONGLEY, P. A.; GOODCHILD, M. F; MANGUIRE, D. J.; RHIND, D. W. 2013. Sistemas e ciência da informação geográfica. Trad. André Schneider o outros. $3 a$ ed. Porto Alegre: Bookman, 2013.

NUNES, F. G. Análise exploratória espacial de indicadores de desenvolvimento socioambiental das regiões de planejamento do norte e nordeste goiano. Ateliê Geográfico, Goiânia: UFG, v. 7, p. 237-259, 2013.

OLIVEIRA, T. J. A. Interações produtivas no estado de Tocantins: uma análise espacial. Dissertação (Mestrado em Desenvolvimento Regional) - Programa de Pós-graduação em Desenvolvimento Regional, Universidade Federal do Tocantins, Palmas, 2012.

PNUD. PROGRAMA DAS NAÇÕES UNIDAS PARA O DESENVOLVIMENTO; IPEA. INSTITUTO DE PESQUISA ECONÔMICA APLICADA; FJP. FUNDAÇÃO JOÃO PINHEIRO. Atlas do Desenvolvimento Humano no Brasil. 2013. CD-ROM.

ROSA, R. Geotecnologias na geografia aplicada. Revista do Departamento de Geografia, V. 16, p. 81-90, 2005.

SANTOS, L.; RAIA JUNIOR, A. A. Análise espacial de dados geográficos: a utilização da Exploratory Spatial Data Analysis - ESDA para identificação de áreas críticas de acidentes de trânsito no município de São Carlos (SP). Sociedade $\mathcal{E}$ Natureza, Uberlândia, v.18, n. 35, p. 97-107, 2006.

SILVA, A. B. Sistemas de informações geo-referenciadas. São Paulo: Ed. Unicamp, 2003. 